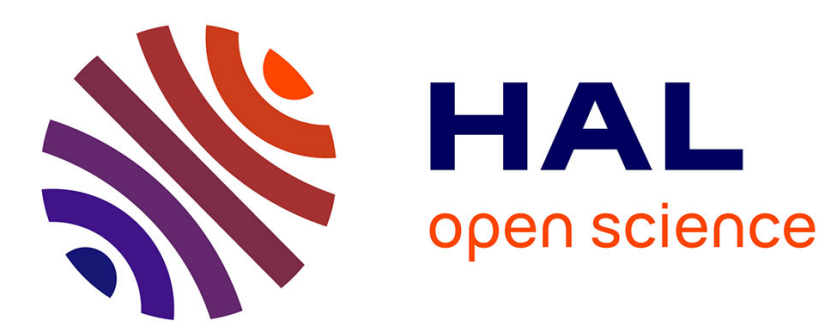

\title{
Micro and macroarchitectural changes at the tibia after botulinum toxin injection in the growing rat
}

\author{
Béatrice Bouvard, Guillaume Mabilleau, Erick Legrand, Maurice Audran, \\ Daniel Chappard
}

\section{- To cite this version:}

Béatrice Bouvard, Guillaume Mabilleau, Erick Legrand, Maurice Audran, Daniel Chappard. Micro and macroarchitectural changes at the tibia after botulinum toxin injection in the growing rat. Bonr, 2012, 50 (4), pp.858-864. 10.1016/j.bone.2011.12.023 . hal-00833684

\section{HAL Id: hal-00833684 \\ https://hal.science/hal-00833684}

Submitted on 13 Jun 2013

HAL is a multi-disciplinary open access archive for the deposit and dissemination of scientific research documents, whether they are published or not. The documents may come from teaching and research institutions in France or abroad, or from public or private research centers.
L'archive ouverte pluridisciplinaire HAL, est destinée au dépôt et à la diffusion de documents scientifiques de niveau recherche, publiés ou non, émanant des établissements d'enseignement et de recherche français ou étrangers, des laboratoires publics ou privés. 
Micro and macroarchitectural changes at the tibia after botulinum toxin injection in the growing rat

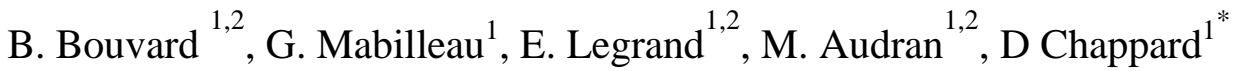 \\ ${ }^{1}$ INSERM, U922 - LHEA, Faculté de Médecine, 49045 ANGERS Cedex - FRANCE. \\ ${ }^{2}$ Service de Rhumatologie - CHU d'Angers, 49933 ANGERS Cedex - FRANCE. \\ e-mail: daniel.chappard@univ-angers.fr \\ doi: 10.1016/j.bone.2011.12.023.
}

Keywords: osteoporosis, microCT, botulinum toxin, disuse, microarchitecture, macroarchitecture

\begin{abstract}
The aim of this study was to analyze bone microarchitecture and macroarchitecture of tibia in a disuse model in growing rats. Eight-weeks-old Copenhagen rats were injected intramuscularly with 1.5 units BTX in the quadriceps muscle of the right hind limb. Saline injection was done at the left hind limb to serve as control. Five rats were killed at day 1 and represented the baseline group (D1), 5 rats were killed at day 14 (D14), 5 at day 21 (D21), 5 at day 28 (D28) and 5 at day 35 (35). For each group, muscle surface, parameters of bone microarchitecture and macroarchitecture (including length, width and curvature of the tibia) were measured using microtomography. Paralysis occurred as soon as day 2 . At the left hind limb, muscle surface area, cortical thickness, cross sectional total area and growth in length significantly increased during the time study. At the right hind limb, muscle surface area, bone trabecular volume, and cortical thickness decreased as soon as day 14 associated with an increased cortical porosity. Growth in length did not differ from left side; cross sectional total area did not increase and the diaphyseal cross section acquired a more rounded shape. There was no modification of the curvature between right and left hind limbs during the time study. In this murine model of unilateral muscle paralysis in growing animals, we showed a rapid muscle loss leading to a decreased growth in width; however growth in length and curvature were unaltered.
\end{abstract}

\title{
INTRODUCTION
}

Bone and muscle grow in proportion to one another. The development of long bones is characterized by endochondral ossification at the epiphyseal growth plates and periosteal expansion at the diaphysis. These processes cause large increments in bone length and cross-sectional diameter, respectively. Regulation of longitudinal and width growths is complex, controlled by systemic, local paracrine and local mechanical factors [1]. Muscles impose large load on bone and skeletal unloading induces both muscle and bone loss. Likewise, variation in muscle size, morphology and volume can also influence bone shape. In humans, spinal cord injury induces a rapid and profound muscle mass loss. This is accompanied by a severe degeneration of function and subsequently a rapid decrease in trabecular and cortical bone with an alteration of bone microarchitecture and macroarchitecture [2,3]. Conversely, previous studies in humans 
have shown that an exercise-induced increment in muscle size during growth was positively correlated with changes in bone mass, size, and strength [4-6]. This biomechanical link between muscle and bone supports the concept of a 'functional muscle-bone unit' [5]. The capacity of bone to respond to mechanical strains by increasing in strength appears more important during the growth period. Bones have special angulations and curvatures which are genetically and epigenetically determined and enable them to resist compression, tension, or torsional (shearing stress) loads [7, 8]. When a growing bone is not subjected to mechanical loading, muscle size and function are reduced and bone lacks the shape necessary for its function [9]. A number of animal models for studying the influence of disuse on bone have been proposed [10]. Surgical methods (denervation [11], spinal section, tenotomy [12], arthrodesis [13]...) were the first used since they induce a rapid bone loss. However, it has been shown that bone loss results from cumulative effects of the disuse and the regional acceleratory phenomenon (RAP) caused by the surgical trauma [14]. At the present time, nonsurgical methods such as immobilization by casting, bandaging [10, 15] or tail suspension are preferred. Transient muscle paralysis caused by botulinum toxin A (BTX) has been found to provoke a rapid bone loss with the cessation of active muscle contraction [16]. Once internalized in neurons, BTX cleaves synaptosome-associated protein 25 (SNAP-25), a protein responsible for binding acetylcholine vesicles to the presynaptic membrane and thus acts by blocking its signaling at the neuromuscular junction [17]. This model avoids the disruption of central nervous system signaling and the irreversibility induced by surgical methods. The aim of our study was to evaluate in young growing rats receiving a single BTX injection, the parallel evolution of muscle and bone mass and the micro and macroarchitecture changes of the immobilized bones. Measures were performed using a microcomputed tomograph (microCT).

\section{METHODS}

\section{Animals and experimental procedures}

Twenty-five eight-weeks-old Copenhagen rats were used in the present study. Rats were maintained on commercial rodent chow (UAR, France) and water was available ad libitum. They were housed in a room maintained at $24^{\circ} \mathrm{C}$ with a 12 -h light/dark cycle. The animal ethical committee of University of Angers approved all procedures used. Rats were randomized into 5 groups (D1, D14, D21, D28 and D35) with 5 animals in each. Rats of the group D1, which constituted the baseline group, were killed at day 1 by $\mathrm{CO}_{2}$ inhalation. At day 1, rats in groups D14, D21, D28 and D35 were injected intramuscularly with 1.5 units BTX (Botox ${ }^{\circledR}$, Allergan, Inc.) dissolved in 0.2 $\mathrm{mL}$ saline in the quadriceps muscle of the right hind limb. They were similarly injected with saline in the left hind limb which served as internal control. Injections were performed under anesthesia by isoflurane inhalation. Rats in groups D14, D21, D28 and D35 were killed respectively at day 14 , day 21 , day 28 , and day 35 . Body mass (g) was monitored each week. Gait disability was assessed referring to the scale described by Warner et al. assessed as follows: (1) hind limb abduction during tail suspension, (2) toe extension during sitting, (3) use of right leg during level walking, (4) use of right leg during two legged stance, and (5) use of right leg during climbing. With a range of 0-2 points for each of the 5 observations, the total possible score for each observation ranged from "0" (completely disabled) to "10" (normal) [18]. After euthanasia, animals were analyzed by microCT (see below), and then, the right and left tibias were carefully 
dissected, placed in an ethanol/formalin fixative for 24 hours and transferred to absolute acetone until use.

\section{Microcomputed tomography (microCT)}

MicroCT analyses were performed soon after euthanasia using a Skyscan 1076 X-ray microcomputed microtomograph (Skyscan, Kontich, Belgium) equipped with an X-ray tube working at $80 \mathrm{kV} / 120 \mu \mathrm{A}$. Rats were installed on a carbon composite bed with diameter $68 \mathrm{~mm}$, length of $400 \mathrm{~mm}$ and maximal scanning length of $200 \mathrm{~mm}$. The pixel size was fixed at $9 \mu \mathrm{m}$ and the rotation step $0.30^{\circ}$, and exposure was done with a $1 \mathrm{~mm}$ aluminum filter. Rats were immobilized in a dorsal decubitus position with legs blocked by plasticine. The two hind limbs of each rat were scanned from the upper to distal epiphysis.

\section{Muscle measurements}

For each leg, a stack of 2D-sections was obtained. Reconstruction of 3D models from this stack was done with the ANT software (Skyscan, release 2.4). For each hind limb, two models were created, one after bone segmentation, the other after muscle segmentation. The two models were overimposed and re-slicing was done in order to obtain a perfectly orthogonal section to the long axis of the tibia just under the growth plate. The CtAn software (Skyscan, release 1.10.1.0) was used to measure the muscle cross sectional area (MCSA, in $\mathrm{mm}^{2}$ ).

\section{Bone measurements}

Bone mass and microarchitecture at the tibia metaphysis were measured with the same software. The volume of interest comprised both the primary and secondary spongiosae (2.5 mm, 264 sections). The volume of interest (VOI) was designed by drawing interactively polygons on the $2 \mathrm{D}$ sections. Only a few number of polygons need to be drawn (e.g. on the first section, several at the middle, and on the final section) since a routine facility calculated all the intermediary masks by interpolation. The VOI comprised only trabecular bone and the marrow cavity. Bone was segmented from soft tissues after thresholding. The following parameters were measured according to recent guidelines and nomenclature proposed by the American Society for Bone and Mineral Research [19].

- Trabecular bone volume $\left(\mathrm{BV} / \mathrm{TV}_{3 \mathrm{D}}\right.$, in \%) represents the percentage of the cancellous space occupied by trabecular bone in the VOI.

- Trabecular thickness (Tb. Th $3 \mathrm{D}$, in $\mu \mathrm{m})$, trabecular separation (Tb.Sp $3 \mathrm{D}$, in $\mu \mathrm{m})$, and trabecular number (Tb. $\mathrm{N}_{3 \mathrm{D}}$, in $/ \mathrm{mm}$ ) provide a full description of bone microarchitecture.

- Structure model index (SMI) indicates the composition of trabecular bone in the form of rods or plates. SMI values are comprised between zero (ideal plate structure model) and three (ideal rod structure).

- Trabecular pattern factor (Tb.P $\mathrm{P}_{\mathrm{f}}$ ) is an index of trabecular connectivity. Tb. $\mathrm{P}_{\mathrm{f}}$ is low in a well-connected structure and high in a disconnected trabecular network.

Cortical thickness was separately measured on 2D sections at the metaphysis (at the last section of the secondary spongiosa) and at the mid-diaphysis $(7.5 \mathrm{~mm}, 800$ sections below)(Figure 1A). Cortical porosity was measured at the diaphysis on the same sections. 


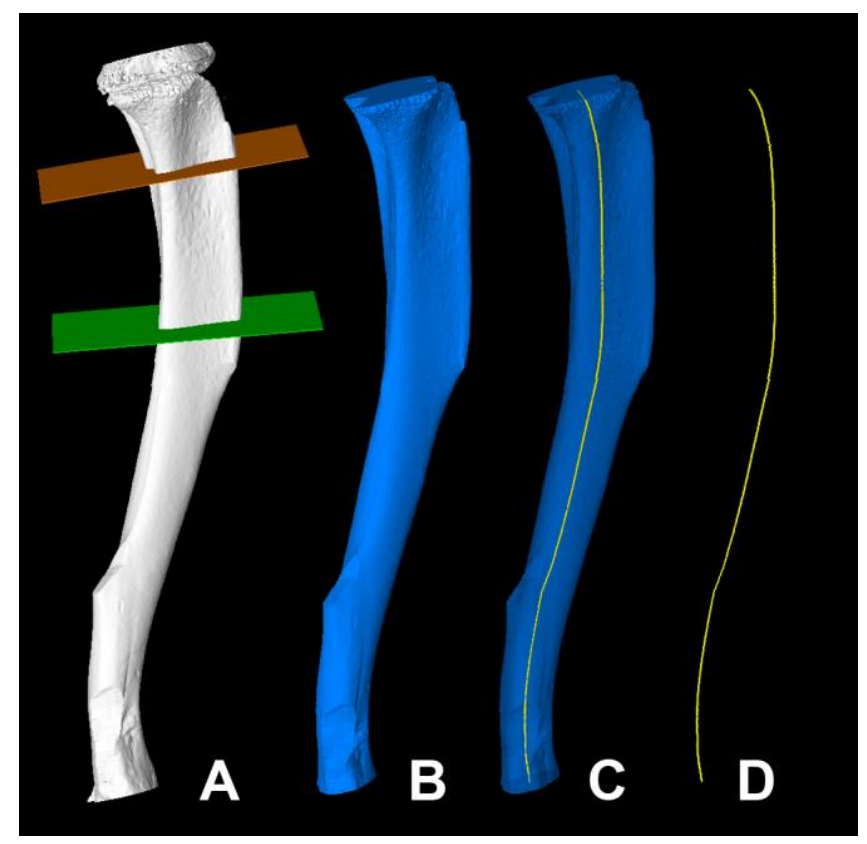

Figure 1 Determination of the line of mass centers by image analysis. A) Reconstruction of the whole bone with position of the 2 sectioning planes used to determine cortical parameters. B) 3D model of the bone in a blue pseudocolor, with filled medullar cavity; C) 3D models of the bone (with a 50\% transparency) and the line of mass centers (in yellow pseudocolor). These combined models are used to orient the bone in the 3D space with the tibia crest on the right. D) 3D model of the line of mass centers suitable for determination of the $x^{3}$ polynomial equation.

\section{Determination of macroarchitectural characteristics of the tibias}

Tibia length was measured as the average distance between the distal articular center (the middle of the talar trochlear facet) and the two proximal articular centers (medial and lateral plateau) using a caliper with an accuracy of $\pm 0.02 \mathrm{~mm}$ (Digitamic, Mitutoyo, USA).

Tibia curvature was determined in the 3D space as the curve joining the mass centers of all sections of the tibia shaft. Briefly, sections of the upper epiphysis to the primary spongiosa were excluded as well as the most distal sections of the lower epiphysis. The 2D stacks of images were transferred to a Leica Q550 image analyzer and a special Quips program was written to automatically determine the mass center of each bone section. On a 2D section, filtering and image openings were applied to eliminate the transcortical vascular channels that could interfere with cortex identification. After segmentation, the marrow cavity was filled and the mass center was determined by a mathematical morphology routine of the analyzer. Two new stacks of sections were saved: the $1^{\text {st }}$ one contained binary images of the filled bone section, the $2^{\text {nd }}$ one a single dot at the mass center of the bone. These 2 new stacks of $2 \mathrm{D}$ sections were used with the ANT software to produce 3D models of the bone and the line of mass centers. The 2 models were automatically aligned and the bone was rendered semi-transparent (Figure 1B-C-D). In the 3D space, the 2 models were positioned so that the tibia crest was always in the same position which provided the best visualization of the bone curvature. 
An image of the line of mass centers was saved. A MATLAB program was written (MATLAB, MathWorks, release R2010b) which converted the image into a file with the $x y$ coordinates of each point of the line. Determination of the equation which described the points was done using TableCurve 2D (Systat Inc, release 5.01). The value of the coefficient of correlation $\mathrm{R}^{2}$ was calculated using the $\mathrm{x}^{3}$ polynomial regression (equation \#2040).

\section{Tibia geometry in cross sections}

The software ImageJ (NIH, http://rsb.info.nih.gov/ij/index.html ) was used to measure cross sectional total area (CSTA), perimeter (CSPm) and cross sectional internal area (CSIA) at the diaphysis and at the metaphysis of each tibia. A form factor (roundness) was derived from these measurements. Roundness is defined as $=4 * \pi *$ CSTA/CSPm${ }^{2}$. The roundness of an object lies in the range $(0,1)$, with a circle giving the highest value of 1; this parameter reflects modification of the bone shape in cross section. The plugin BoneJ (BoneJ.org, release 1.2.4) [20] was used to quantify the second moment of inertia of the cross section (I) along the anteroposterior (Iap), the mediolateral (Iml) axis, and the polar section modulus in the anteroposterior (Zap) and mediolateral (Zml) axes. The polar moment of inertia (J) was defined afterwards using the formula $\mathrm{J}=\mathrm{Iap}+\mathrm{Iml}$ [21-23]. These measurements were done at the diaphysis and at the metaphysis for each tibia using the same 2D sections used to measure cortical thickness. The second moment of area measures the ability of the tibia to resist bending. The polar section modulus and the polar moment of inertia measure the ability of tibia to resist torsion.

\section{Statistical analysis}

Statistical analysis was performed using the Systat statistical software release 13.0 (Systat Software Inc., San Jose, CA). All data were expressed as mean \pm standard error of the mean (SEM). Differences between groups were analyzed by a non-parametric ANOVA test (Kruskall-Wallis). The Mann and Whitney test was performed to compare the right and left sides within a group. Differences were considered significant when $p$ $<0.05$.

\section{RESULTS}

\section{General findings}

At the onset of the study, the weight of the rats was $172.24 \pm 1.72 \mathrm{~g}$ without any difference in the five groups. No rat died during the study. Gait dysfunction was detectable within the first 24 hours in all groups with an inability to spread toes while seated and with difficulty to hind limb abduction during tail suspension. All rats could climb, walk and stay in stance on their two hind limbs. Maximum score of gait disability was 5/10 observed since day 2 to day 14, then animals recovered from paralysis which was clinically undetectable at day 35 .

\section{Muscle mass}

At the beginning of the study, there was no difference between MCSA at the left and the right hind limb in each group. MCSA at the left hind limb progressively increased with a total gain of $21 \%(\mathrm{p}<0.05)$ at the end of the study. MCSA at the right hind limb 
decreased rapidly $(-40 \%$ at day $14(\mathrm{p}<0.0001)$ followed by a plateau and a tendency to increase at D28. MCSA at the right hind limb was statistically lower than at the left side in all groups excepted D1 (Table 1 and Figure 2).

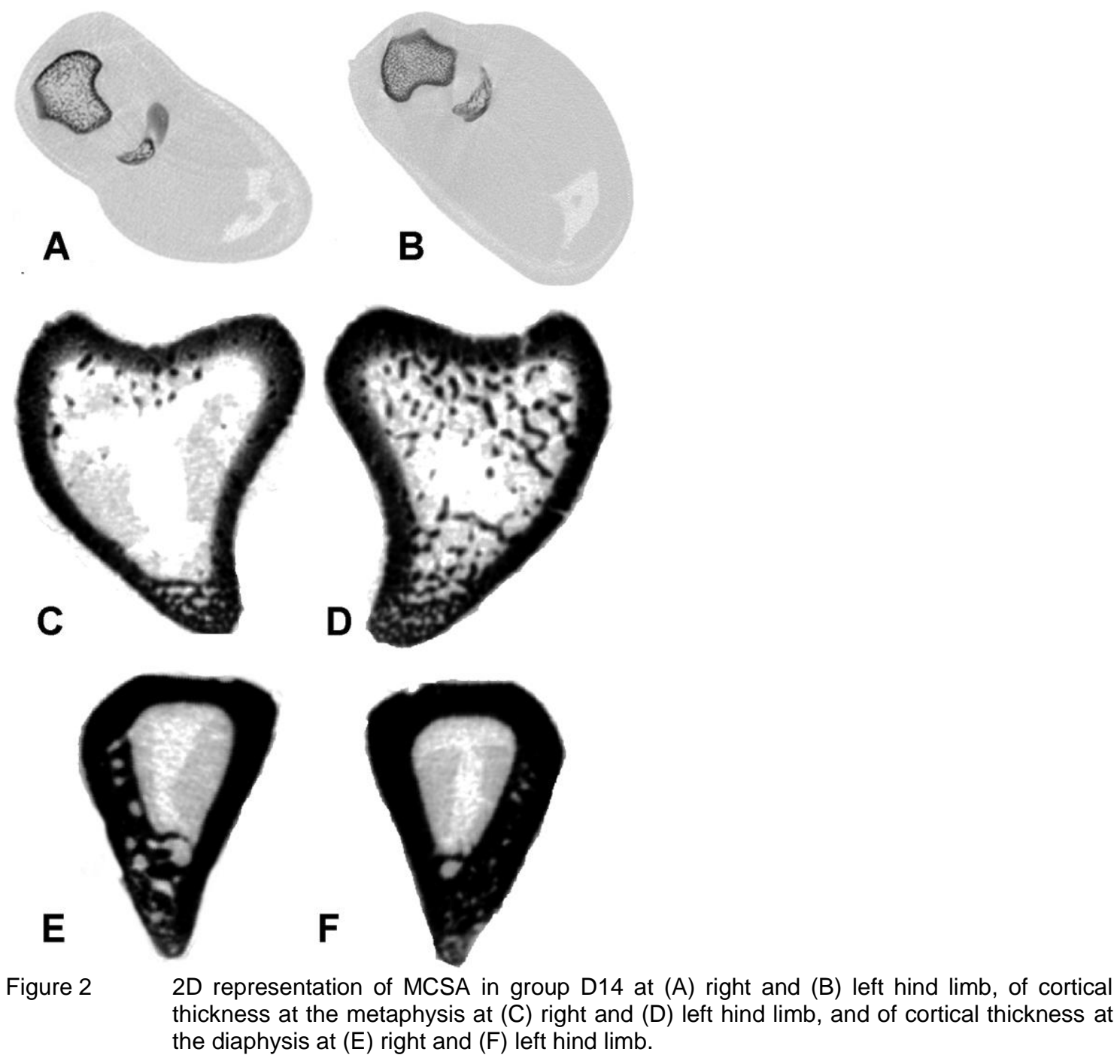

\section{Bone analysis}

Table 1 summarizes the results of microCT measurements. There was no significant difference between groups at the beginning of the study for the different parameters. From day 14 to 35, BV/TV, Tb.Th, Tb.N were significantly decreased at the right hind limb and conversely Tb.Sp, Tb.P $\mathrm{P}_{\mathrm{f}}$ and SMI were significantly increased compared with the left hind limb. However, limited recovery seemed to begin at day 21 at the right hind limb, since Tb.Th increased. Cortical thickness significantly increased at the diaphysis and metaphysis at left hind limb during the study. At the right hind limb cortical thickness at the diaphysis was significantly decreased in D14 and D21 groups compared with left hind limb. Cortical porosity was significantly increased at the right hind limb in all groups excepted D1 compared with left hind limb.

\section{Growth in length and width}


Bone. 2012 Apr;50(4):858-64

Table 2 shows the macroarchitectural parameters. There was a significant increase in length of both the right tibia and the left tibia without any differences between right and left hind limb. At both the diaphysis and metaphysis, CSTA was significantly increased at the left hind limb without any significant increase of CSIA; there was no significant increase of CSTA and CSIA at the right hind limb. 


\begin{tabular}{|c|c|c|c|c|c|c|c|c|c|c|}
\hline & \multicolumn{2}{|c|}{ D1 } & \multicolumn{2}{|c|}{ D14 } & \multicolumn{2}{|c|}{ D21 } & \multicolumn{2}{|c|}{ D28 } & \multicolumn{2}{|c|}{ D35 } \\
\hline & Left & Right & Left & Right & Left & Right & Left & Right & Left & Right \\
\hline Rat weight (gr) & \multicolumn{2}{|c|}{$179 \pm 3$} & \multicolumn{2}{|c|}{$188 \pm 5^{*}$} & \multicolumn{2}{|c|}{$198 \pm 6^{*}$} & \multicolumn{2}{|c|}{$217 \pm 4^{*}$} & \multicolumn{2}{|c|}{$214 \pm 9 *$} \\
\hline Tibia length (mm) & $30.42 \pm 0.17$ & $30.77 \pm 0.15$ & $30.81 \pm 0,28$ & $31.21 \pm 0.31$ & $31.79 \pm 0.29 *$ & $31.82 \pm 0.28 *$ & $32.60 \pm 0.24 *$ & $32.09 \pm 0.14 *$ & $33.76 \pm 0.24 *$ & $33.63 \pm 0.63^{*}$ \\
\hline $\operatorname{MCSA}\left(\mathrm{mm}^{2}\right)$ & $218 \pm 5$ & $215 \pm 8$ & $200 \pm 8$ & $129 \pm 6^{*}$ & $209 \pm 7$ & $125 \pm 4.12 *$ & $242 \pm 11$ & $136 \pm 9 *$ & $276 \pm 23 *$ & $147 \pm 11^{*}$ \\
\hline $\mathrm{BV} / \mathrm{TV}(\%)$ & $19.39 \pm 1.23$ & $18.65 \pm 1.47$ & $17.97 \pm 1.22$ & $8.39 \pm 0.63^{*}$ & $20.78 \pm 2.05$ & $9.27 \pm 1.12 *$ & $21.82 \pm 0.55$ & $12.04 \pm 0.65^{*}$ & $19.74 \pm 1.23$ & $9.65 \pm 0.71 *$ \\
\hline Tb.Th $(\mu \mathrm{m})$ & $73 \pm 2$ & $70 \pm 2$ & $74 \pm 1$ & $64 \pm 1 *$ & $81 \pm 2 *$ & $70 \pm 2$ & $83 \pm 1 *$ & $74 \pm 1$ & $84 \pm 2 *$ & $74 \pm 1$ \\
\hline Tb.N (/mm) & $2.66 \pm 0.09$ & $2.64 \pm 0.14$ & $2.44 \pm 0.12$ & $1.32 \pm 0.09 *$ & $2.54 \pm 0.20$ & $1.31 \pm 0.14^{*}$ & $2.63 \pm 0.04$ & $1.61 \pm 0.07 *$ & $2.36 \pm 0.11$ & $1.28 \pm 0.07 *$ \\
\hline Tb.Sp $(\mu \mathrm{m})$ & $213 \pm 4$ & $221 \pm 14$ & $240 \pm 8^{*}$ & $388 \pm 28^{*}$ & $254 \pm 29^{*}$ & $456 \pm 32 *$ & $232 \pm 5^{*}$ & $404 \pm 22 *$ & $260 \pm 13^{*}$ & $487 \pm 34^{*}$ \\
\hline Tb.P $P_{f}$ & $13.50 \pm 0.94$ & $13.33 \pm 0.89$ & $13.92 \pm 0.87$ & $21.96 \pm 0.68 *$ & $12.04 \pm 1.13$ & $20.37 \pm 1.28 *$ & $11.23 \pm 0.39$ & $17.65 \pm 0.78 *$ & $12.58 \pm 0.66$ & $19.55 \pm 0.61 *$ \\
\hline SMI & $1.83 \pm 0.04$ & $1.77 \pm 0.05$ & $1.88 \pm 0.05$ & $2.29 \pm 0.03^{*}$ & $1.83 \pm 0.1$ & $2.31 \pm 0.06^{*}$ & $1.78 \pm 0.03$ & $2.19 \pm 0.03 *$ & $1.91 \pm 0.05$ & $2.32 \pm 0.04 *$ \\
\hline Porosity (\%) & $1.22 \pm 0.14$ & $1.30 \pm 0.43$ & $1.71 \pm 0.61$ & $4.93 \pm 0.7 *$ & $1.09 \pm 0.21$ & $2.79 \pm 0.53$ & $0.39 \pm 0.15^{*}$ & $1.10 \pm 0.20$ & $0.96 \pm 0.4$ & $2.55 \pm 0.69$ \\
\hline Ct.Th M $(\mu \mathrm{m})$ & $192 \pm 8$ & $193 \pm 6$ & $208 \pm 9$ & $174 \pm 10^{*}$ & $231 \pm 4^{*}$ & $198 \pm 8$ & $222 \pm 9^{*}$ & $244 \pm 11^{*}$ & $250 \pm 8^{*}$ & $271 \pm 12^{*}$ \\
\hline Ct.Th D $(\mu \mathrm{m})$ & $345 \pm 8$ & $346 \pm 12$ & $361 \pm 12$ & $265 \pm 13^{*}$ & $375 \pm 10 *$ & $287 \pm 9 *$ & $407 \pm 19 *$ & $362 \pm 13$ & $402 \pm 22 *$ & $333 \pm 15$ \\
\hline
\end{tabular}

MCSA: muscle cross-sectional area; BV/TV: trabecular volume; Tb.Th: trabecular thickness; Tb.N: trabecular number; Tb.Sp: trabecular separation; Tb.P $\mathrm{f}_{\mathrm{f}}$ trabecular pattern factor; SMI: structural Model Index; Ct.Th: cortical thickness; M: metaphysis; D: diaphysis

$* \mathrm{p}<0.05$ vs D1

Gray box $\mathrm{p}<0.05$ vs left 
Bone. 2012 Apr;50(4):858-64

\begin{tabular}{|c|c|c|c|c|c|c|c|c|c|c|}
\hline & \multicolumn{2}{|c|}{ D1 } & \multicolumn{2}{|c|}{ D14 } & \multicolumn{2}{|c|}{ D21 } & \multicolumn{2}{|c|}{ D28 } & \multicolumn{2}{|c|}{ D35 } \\
\hline & Left & Right & Left & Right & Left & Right & Left & Right & Left & Right \\
\hline $\begin{array}{l}\text { CSTA M } \\
\left(\mathrm{mm}^{2}\right)\end{array}$ & $5.28 \pm 0.31$ & $5.25 \pm 0.36$ & $5.37 \pm 0.32$ & $5.48 \pm 0.08$ & $5.90 \pm 0.18$ & $5.59 \pm 0.14$ & $6.10 \pm 0.18 *$ & $5.57 \pm 0.16$ & $6.12 \pm 0.32 *$ & $5.39 \pm 0.32$ \\
\hline $\begin{array}{l}\text { CSIA M } \\
\left(\mathrm{mm}^{2}\right)\end{array}$ & $3.11 \pm 0.13$ & $3.04 \pm 0.23$ & $3.30 \pm 0.20$ & $3.51 \pm 0.09$ & $3.41 \pm 0.18$ & $3.39 \pm 0.17$ & $3.66 \pm 0.16$ & $3.17 \pm 0.14$ & $3.51 \pm 0.20$ & $2.86 \pm 0.17$ \\
\hline $\begin{array}{l}\text { CSTA D } \\
\left(\mathrm{mm}^{2}\right)\end{array}$ & $3.08 \pm 0.15$ & $3.07 \pm 0.19$ & $3.30 \pm 0.07$ & $3.01 \pm 0.16$ & $3.54 \pm 0.09 *$ & $3.27 \pm 0.09$ & $3.62 \pm 0.10^{*}$ & $3.28 \pm 0.13$ & $3.67 \pm 0.18^{*}$ & $3.25 \pm 0.15$ \\
\hline $\begin{array}{l}\text { CSIA D } \\
\left(\mathrm{mm}^{2}\right)\end{array}$ & $0.95 \pm 0.05$ & $0.96 \pm 0.05$ & $0.96 \pm 0.03$ & $0.94 \pm 0.04$ & $1.00 \pm 0.05$ & $1.04 \pm 0.05$ & $0.98 \pm 0.04$ & $0.99 \pm 0.08$ & $0.98 \pm 0.05$ & $0.99 \pm 0.05$ \\
\hline $\begin{array}{l}\text { Tibia length } \\
(\mathrm{mm})\end{array}$ & $30.42 \pm 0.17$ & $30.77 \pm 0.15$ & $30.81 \pm 0.28$ & $31.21 \pm 0.31$ & $31.79 \pm 0.29^{*}$ & $31.82 \pm 0.28^{*}$ & $32.60 \pm 0.24 *$ & $32.09 \pm 0.14 *$ & $33.76 \pm 0.24 *$ & $33.63 \pm 0.63^{*}$ \\
\hline $\begin{array}{l}\text { Curvature } \\
\left(\mathrm{R}^{2}\right)\end{array}$ & $0.96 \pm 0.01$ & $0.97 \pm 0.01$ & $0.97 \pm 0.01$ & $0.97 \pm 0.01$ & $0.97 \pm 0.004$ & $0.97 \pm 0.003$ & $0.96 \pm 0.005$ & $0.963 \pm 0.004$ & $0.970 \pm 0.005$ & $0.97 \pm 0.003$ \\
\hline
\end{tabular}

CSTA: cross sectional total area, CSIA: cross sectional intra area, M: metaphysis, D: diaphysis, $\mathrm{R}^{2}$ : coefficient of correlation of the equation of tibia curvature using the $\mathrm{x}^{3}$ polynomial regression

\section{$* \mathrm{p}<0.05$ vs D1}

Gray box $\mathrm{p}<0.05 v s$ left 


\section{Cross-sectional geometric properties}

Table 2 shows the cross-sectional geometric properties. The roundness at the diaphysis tended to increase on the right side at D21 and became significantly different in group D35 with a more rounded shape at right hind limb (Figure 3). The significant increase of CSTA (reflecting periosteal apposition of the left hind limb) led to an increase in torsion and bending resistance at the diaphysis as evidenced by a significant increase of I, J and Z (Figure 4). However, there was no significant increase at the metaphysis. At the right hind limb, there was no significant increase of $\mathrm{I}, \mathrm{J}$ and $\mathrm{Z}$ at both the diaphysis and metaphysis, during the whole study.

\section{Bone curvature}

There was no change in curvature of the tibia during the study and no difference could be observed between right and left hind limbs.
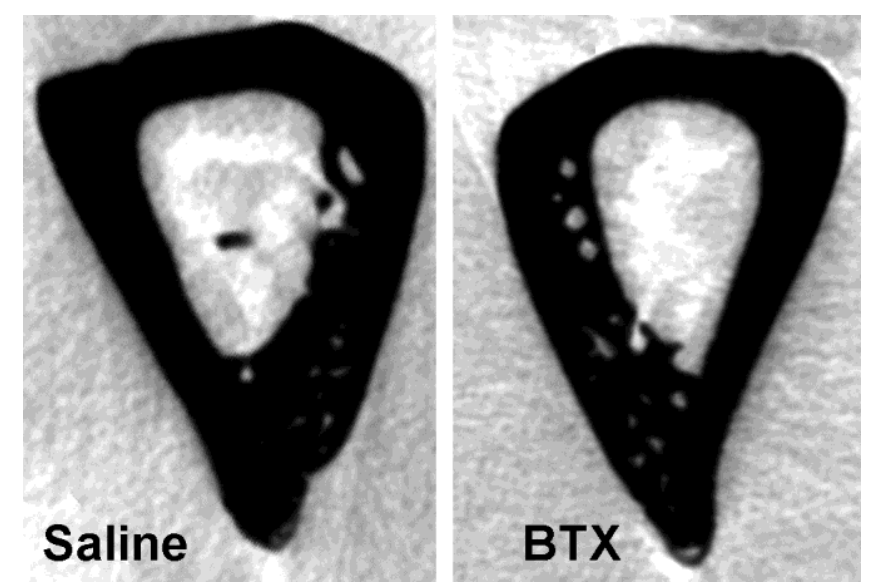

Figure 3

$2 \mathrm{D}$ sections at the diaphysis showing difference in roundness of the tibia shaft 

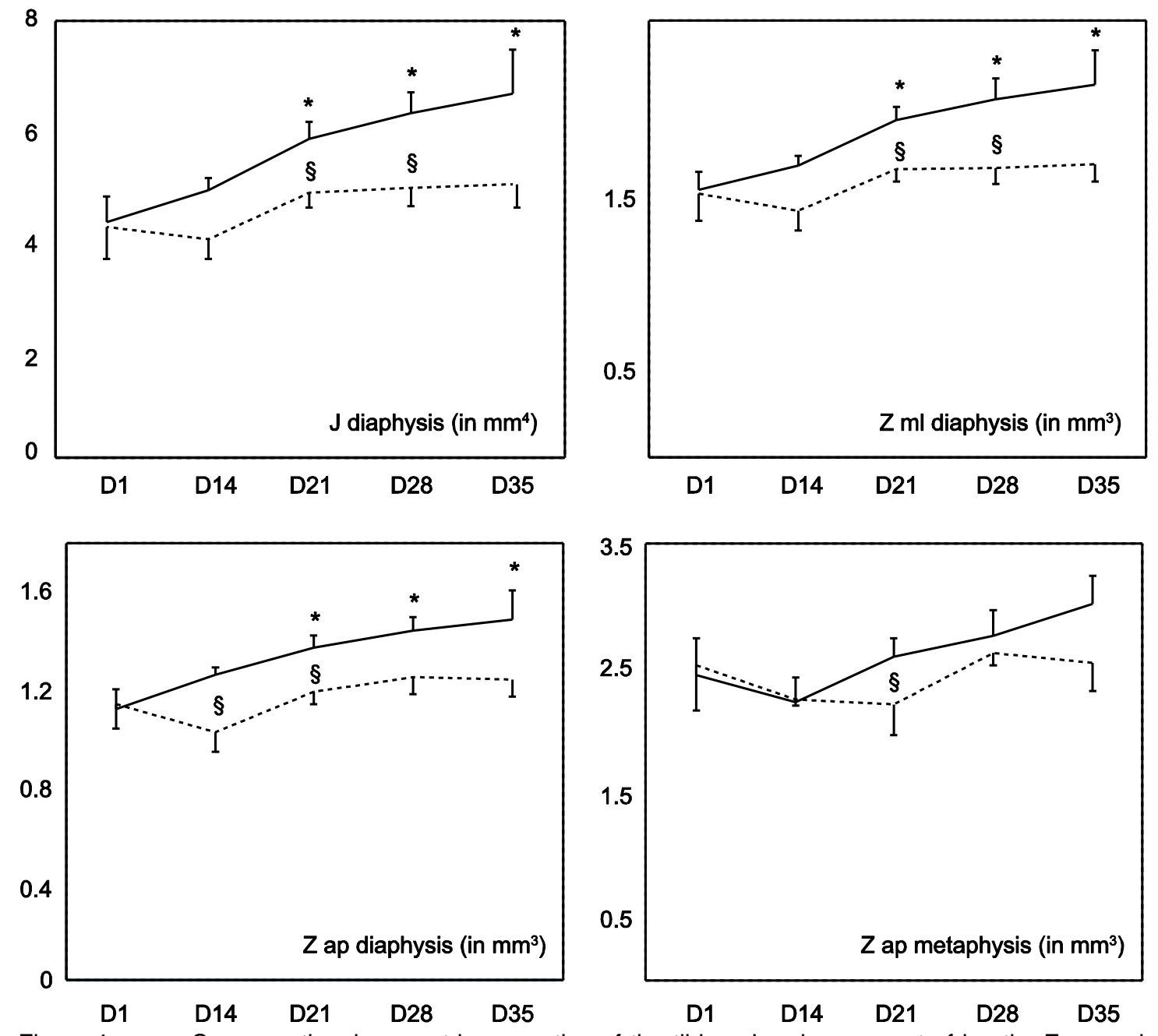

Figure 4 Cross-sectional geometric properties of the tibias. J: polar moment of inertia, Z ap: polar section modulus in anteroposterior axis, $Z \mathrm{ml}$ : polar section modulus in mediolateral axis. Left hind limb: plain line; Right hind limb: dashed line. * $p<0.05$ vs $D 1 ; \S \quad p<0.05$ vs left hind limb.

\section{DISCUSSION}

The capacity of bone to respond to mechanical loading with increased strength is maximal during growth; furthermore muscle recovery is known to be better in young than in older rats [24]. In the present study, disuse was induced in growing rats to obtain a rapid bone loss at both cortical and trabecular compartments associated with muscle loss. BTX induced paralysis is a well-known model which has been already used in rats [16, 25, 26], mice [18, 27-30] and rabbits [31]. Unlike neurectomy, BTX injection paralyzes rapidly the skeletal muscles with recovery occurring in a few weeks [17]. The dose of 1.5 units of BTX seems to be harmless without any systemic effect; rats gained weight and were able to move normally. MicroCT allows conjointly the analysis of both muscle and bone and has been previously used to measure bone and muscle loss after BTX injection in mature mice [28, 30]. The kinetic of bone and muscle loss and their recovery are variable and depend on the age and animal species. It is also function of the BTX dose and of the point of injection. Previous studies done in 
growing rats using 6 Units BTX/1000 gr showed a maximal muscle atrophy at 2 weeks, then a plateau in muscle recovery between 2 weeks and 3 months post-injection and a return to nearly normal at 6 months post injection [32]. In our study, BTX led to an important and rapid muscle loss as previously described; it was maximal in group D14 as evidenced by a decrease in MCSA reaching $40 \%$. Bone loss was also rapid and maximal in group D14, both in cortical and trabecular compartments. Trabecular loss was greater than cortical loss. Trabecular bone recovery began with an increased trabecular thickness since D21. Cortical bone loss was in part achieved by expansion of the endocortical surface due to an extensive increase resorption and as evidenced by an increased CSIA at the metaphysis. At the left hind limb, we observed a progressive and significant growth in length and a significant growth in width at both the metaphysis and diaphysis. At the right hind limb, growth in length was not modified but the growth in width was reduced, CSTA at the diaphysis and the metaphysis did not increase significantly. The differences between the kinetics at the diaphysal and metaphyseal cortical level may be underlined by difference in the remodeling rate or the possible heterogeneity in the osteoblast population at these two locations as previously described [33]. Growth in length and growth in width have different patterns, and depend on different stimuli. Growth in length relies on endochondral ossification controlled by systemic factors such as growth hormone, insulin-like growth factor, thyroid hormone, sex hormones and local factors [6]. Mechanical control is another stimulus of growth in length; both mild tension and mild compression have positive effects [34]. In our study, rats still used their right hind limb, despite lameness and so, maintained compression on the growth plate which could explain the unaltered growth in length. This confirms that bone length is a significant determinant of bone geometry independent of muscle size [35]. On the other hand, growth in width depends on periosteal expansion, partly controlled by local factors such as mechanical loading. In our study, BTX injection led to a decrease in muscle contraction and a decrease in cortical thickness and CSTA suggesting a reduced periosteal apposition. In individuals with long-standing spinal cord injury, the boundaries of the tibia shaft are often modified so that bone shape becomes round rather than triangular in cross sections. This is particularly evident when spinal cord injury occurs during adolescence [3]. In our study, the form factor roundness increased regularly at the right side from D21 confirming human observations.

Macroarchitectural differences in right hind limb evidenced a reduced growth in width (CSTA) associated with reduced moments of inertia which are known to reflect lower torsion and bending resistances. Bone curvature is also a critical determinant of mechanical bone resistance during skeletal loading. Despite differences in cross sectional geometric parameters at the tibia, bone curvature was not modified at the right side.

In conclusion, we have developed a murine model of unilateral transient muscle paralysis in growing animals that demonstrated rapid degradation of skeletal muscles leading to slow down of growth in width. No impact on bone length growth and no modification of the bone curvature occurred.

\section{Acknowledgments}

This work was funded by a grant from the Bioregos 2 regional contract. 


\section{References}

[1] Rauch F. Bone growth in length and width: the Yin and Yang of bone stability. Journal of musculoskeletal \& neuronal interactions 2005;5:194201.

[2] Sievanen H. Immobilization and bone structure in humans. Archives of biochemistry and biophysics 2010;503:146-52.

[3] Bass SL, Eser P, and Daly R. The effect of exercise and nutrition on the mechanostat. Journal of musculoskeletal \& neuronal interactions 2005;5:239-54.

[4] Turner $\mathrm{CH}$, and Pavalko FM. Mechanotransduction and functional response of the skeleton to physical stress: the mechanisms and mechanics of bone adaptation. J Orthop Sci 1998;3:346-55.

[5] Daly RM, Saxon L, Turner CH, Robling AG, and Bass SL. The relationship between muscle size and bone geometry during growth and in response to exercise. Bone 2004;34:281-7.

[6] van der Eerden BC, Karperien M, and Wit JM. Systemic and local regulation of the growth plate. Endocr Rev 2003;24:782-801.

[7] Bertram JE, and Biewener AA. Bone curvature: sacrificing strength for load predictability? J Theor Biol 1988;131:75-92.

[8] Lanyon LE, and Bourn S. The influence of mechanical function on the development and remodeling of the tibia. An experimental study in sheep. J Bone Joint Surg Am 1979;61:263-73.

[9] Frost HM, and Schonau E. The "muscle-bone unit" in children and adolescents: a 2000 overview. Journal of pediatric endocrinology \& metabolism : JPEM 2000;13:571-90.

[10] Jee WS, and Ma Y. Animal models of immobilization osteopenia. Morphologie 1999;83:25-34.

[11] Conaway HH, Waite LC, and Kenny AD. Immobilization and bone mass in rats. Effects of parathyroidectomy and acetazolamide. Calcif Tissue Res 1973;11:323-30.

[12] Andersson SM, and Nilsson BE. Changes in bone mineral content following ligamentous knee injuries. Med Sci Sports 1979;11:351-3.

[13] Ferguson AB, Jr., and Akahoshi Y. Vascular patterns in immobilized, denervated, or devascularized rabbit limbs. J Bone Joint Surg Am 1960;42-A:617-24.

[14] Frost HM. The regional acceleratory phenomenon: a review. Henry Ford Hosp Med J 1983;31:3-9.

[15] Ijiri K, Jee WS, Ma YF, and Yuan Z. Remobilization partially restored the bone mass in a non-growing cancellous bone site following long term immobilization. Bone 1995;17:213S-17S.

[16] Chappard D, Chennebault A, Moreau M, Legrand E, Audran M, and Basle MF. Texture analysis of X-ray radiographs is a more reliable descriptor of bone loss than mineral content in a rat model of localized disuse induced by the Clostridium botulinum toxin. Bone 2001;28:72-9. 
[17] Huang W, Foster JA, and Rogachefsky AS. Pharmacology of botulinum toxin. Journal of the American Academy of Dermatology 2000;43:24959.

[18] Warner SE, Sanford DA, Becker BA, Bain SD, Srinivasan S, and Gross TS. Botox induced muscle paralysis rapidly degrades bone. Bone 2006;38:257-64.

[19] Bouxsein ML, Boyd SK, Christiansen BA, Guldberg RE, Jepsen KJ, and Muller R. Guidelines for assessment of bone microstructure in rodents using micro-computed tomography. J Bone Miner Res 2010;25:1468-86.

[20] Doube M, Klosowski MM, Arganda-Carreras I, Cordelieres FP, Dougherty RP, Jackson JS, et al. BoneJ: Free and extensible bone image analysis in ImageJ. Bone 2010;47:1076-9.

[21] Modlesky CM, Slade JM, Bickel CS, Meyer RA, and Dudley GA. Deteriorated geometric structure and strength of the midfemur in men with complete spinal cord injury. Bone 2005;36:331-9.

[22] Tommasini SM, Nasser P, Schaffler MB, and Jepsen KJ. Relationship between bone morphology and bone quality in male tibias: implications for stress fracture risk. Journal of bone and mineral research : the official journal of the American Society for Bone and Mineral Research 2005;20:1372-80.

[23] Milgrom C, Giladi M, Simkin A, Rand N, Kedem R, Kashtan H, et al. The area moment of inertia of the tibia: a risk factor for stress fractures. Journal of biomechanics 1989;22:1243-8.

[24] Pattison JS, Folk LC, Madsen RW, and Booth FW. Selected Contribution: Identification of differentially expressed genes between young and old rat soleus muscle during recovery from immobilizationinduced atrophy. Journal of applied physiology 2003;95:2171-9.

[25] Libouban H, Blouin S, Moreau MF, Basle MF, Audran M, and Chappard D. Effects of risedronate in a rat model of osteopenia due to orchidectomy and disuse: densitometric, histomorphometric and microtomographic studies. Micron 2008;39:998-1007.

[26] Blouin S, Gallois Y, Moreau MF, Basle MF, and Chappard D. Disuse and orchidectomy have additional effects on bone loss in the aged male rat. Osteoporosis international : a journal established as result of cooperation between the European Foundation for Osteoporosis and the National Osteoporosis Foundation of the USA 2007;18:85-92.

[27] Ausk BJ, Huber P, Poliachik SL, Bain SD, Srinivasan S, and Gross TS. Cortical bone resorption following muscle paralysis is spatially heterogeneous. Bone 2011.

[28] Poliachik SL, Bain SD, Threet D, Huber P, and Gross TS. Transient muscle paralysis disrupts bone homeostasis by rapid degradation of bone morphology. Bone 2010;46:18-23.

[29] Manske SL, Boyd SK, and Zernicke RF. Muscle changes can account for bone loss after botulinum toxin injection. Calcified tissue international 2010;87:541-9. 
[30] Manske SL, Boyd SK, and Zernicke RF. Muscle and bone follow similar temporal patterns of recovery from muscle-induced disuse due to botulinum toxin injection. Bone 2010;46:24-31.

[31] Rauch F, and Hamdy R. Effect of a single botulinum toxin injection on bone development in growing rabbits. Journal of musculoskeletal \& neuronal interactions 2006;6:264-8.

[32] Ma J, Elsaidi GA, Smith TL, Walker FO, Tan KH, Martin E, et al. Time course of recovery of juvenile skeletal muscle after botulinum toxin $A$ injection: an animal model study. American journal of physical medicine \& rehabilitation / Association of Academic Physiatrists 2004;83:774-80; quiz 81-3.

[33] Candeliere GA, Liu F, and Aubin JE. Individual osteoblasts in the developing calvaria express different gene repertoires. Bone 2001;28:351-61.

[34] Frost HM. Biomechanical control of knee alignment: some insights from a new paradigm. Clin Orthop Relat Res 1997:335-42.

[35] Wetzsteon RJ, Zemel BS, Shults J, Howard KM, Kibe LW, and Leonard MB. Mechanical loads and cortical bone geometry in healthy children and young adults. Bone 2011;48:1103-8.

\section{Conflict of interest: none}

